\title{
Demonstration of Cascaded In-Line Single-Pump Fiber Optical Parametric Amplifiers in
} Recirculating Loop Transmission

Lali-Dastjerdi, Zohreh; Ozolins, Oskars; An, Yi; Cristofori, Valentina; Da Ros, Francesco; Kang, Ning; Hu, Hao; Mulvad, Hans Christian Hansen; Rottwitt, Karsten; Galili, Michael

Total number of authors:

11

Published in:

ECOC Technical Digest

Link to article, DOI:

10.1364/ECEOC.2012.Mo.2.C.5

Publication date:

2012

Document Version

Publisher's PDF, also known as Version of record

Link back to DTU Orbit

Citation $(A P A)$ :

Lali-Dastjerdi, Z., Ozolins, O., An, Y., Cristofori, V., Da Ros, F., Kang, N., Hu, H., Mulvad, H. C. H., Rottwitt, K., Galili, M., \& Peucheret, C. (2012). Demonstration of Cascaded In-Line Single-Pump Fiber Optical Parametric Amplifiers in Recirculating Loop Transmission. In ECOC Technical Digest (pp. Mo.2.C.5). Optical Society of America. https://doi.org/10.1364/ECEOC.2012.Mo.2.C.5

\section{General rights}

Copyright and moral rights for the publications made accessible in the public portal are retained by the authors and/or other copyright owners and it is a condition of accessing publications that users recognise and abide by the legal requirements associated with these rights.

- Users may download and print one copy of any publication from the public portal for the purpose of private study or research.

- You may not further distribute the material or use it for any profit-making activity or commercial gain

- You may freely distribute the URL identifying the publication in the public portal 


\title{
Demonstration of Cascaded In-Line Single-Pump Fiber Optical Parametric Amplifiers in Recirculating Loop Transmission
}

\author{
Z. Lali-Dastjerdi ${ }^{(1)}$, O. Ozolins ${ }^{(1,2)}, \mathrm{Y} . \mathrm{An}^{(1)}, \mathrm{V}$. Cristofori ${ }^{(1)}, \mathrm{F} . \mathrm{Da} \operatorname{Ros}^{(1)}, \mathrm{N} . \mathrm{Kang}^{(1)}, \mathrm{H} \cdot \mathrm{Hu}^{(1)}$, \\ H. C. H. Mulvad ${ }^{(1)}$, K. Rottwitt ${ }^{(1)}$, M. Galili $^{(1)}$, C. Peucheret ${ }^{(1)}$ \\ (1) Department of Photonics Engineering, Technical University of Denmark, DK-2800 Kgs. Lyngby, \\ Denmark, zoda@fotonik.dtu.dk \\ (2) Telecommunications Institute, Riga Technical University, LV-1048, Riga, Latvia
}

\begin{abstract}
The performance of cascaded single-pump fiber optical parametric amplifiers (FOPAs) is experimentally studied for the first time using recirculating loop transmission with $80-\mathrm{km}$ dispersion managed spans. Error-free performance has been achieved over $320 \mathrm{~km}$ for 40 -Gbit/s CSRZ-OOK and CSRZ-DPSK modulated signals.
\end{abstract}

\section{Introduction}

Fiber optical parametric amplifiers (FOPAs) are a promising choice for amplification of data signals outside the erbium-doped fiber amplifiers (EDFAs) band in long-distance optical transmission systems. The gain of FOPAs depends on pump power, fiber nonlinearity and fiber dispersion properties, and can therefore be tailored with respect to the wavelength configuration of the interacting waves and be centered at about any arbitrary wavelength ${ }^{1}$. Other unique aspects of FOPAs, such as the possibility for regeneration using gain saturation and frequency conversion make them even more attractive for multi-functional applications ${ }^{2,3}$. Until now, FOPAs have been mostly used as stand-alone amplifiers or alloptical signal processing elements, and only recently have studies on the implementation of these amplifiers in transmission links been under focus ${ }^{4-6}$. In Ref. 4 the performance of single-pump FOPAs in dense wavelengthdivision multiplexed systems was investigated using a recirculating loop with the FOPA actually used outside of the loop, either as a booster amplifier or at the end of the transmission line. In Ref. 6, the reduction of nonlinear phase noise by an all-optical amplitude limiter using saturation of four-wave mixing in a fiber has been investigated in a recirculating loop transmission. However no gain was provided to the signal in the parametric amplitude regenerator. The use of FOPAs as in-line amplifiers in a multi-span link has, to the best of our knowledge, never been reported so far.

In this paper, we have experimentally investigated for the first time the performance of cascaded single-pump FOPAs using a multispan recirculating loop transmission where a FOPA with $20 \mathrm{~dB}$ on-off gain is located in the transmission line. The cascadability of the FOPA is demonstrated for 40-Gbit/s carrier-suppressed return-to-zero (CSRZ) on-off keying (CSRZOOK) and CSRZ differential-phase shift keying (CSRZ-DPSK) modulated signals. Error-free performance is achieved for both modulation formats over a $320 \mathrm{~km}$ dispersion managed link, thus demonstrating a first step towards the

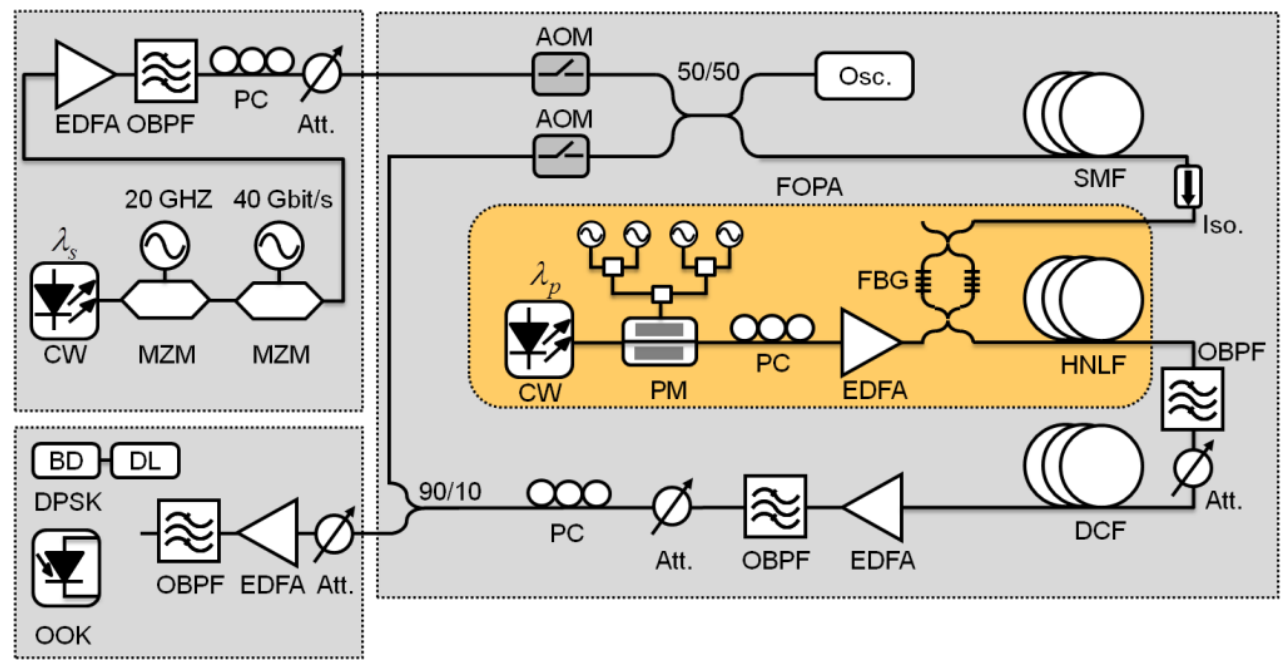

Fig. 1: Experimental setup 
implementation of FOPAs as in-line amplifiers.

\section{Experimental setup}

The experimental setup is shown in Fig. 1. A recirculating loop is used to realize the cascadability investigation of FOPAs. At the transmitter, a $67 \%$ RZ-OOK or RZ-DPSK signal is generated from a continuous wave (CW) laser at $1545 \mathrm{~nm}$ using cascaded Mach-Zehnder modulators (MZMs) used as pulse carver and data modulator, respectively. The data modulator is driven with a $2^{31}-1$ pseudo-random binary sequence (PRBS) at $40 \mathrm{Gbit} / \mathrm{s}$. The modulation format is selected by adjusting the bias and peak-to-peak voltage applied to the data modulator. The modulated signal is then amplified by an EDFA followed by an optical bandpass filter (OBPF) with $3 \mathrm{~nm}$ bandwidth and its power at the loop input is adjusted by an optical variable attenuator (OVA).

The circulations in the loop are controlled by two acousto-optic modulators (AOMs). Data is continuously sent, via a $90 / 10 \%$ coupler, to the receiver. Gating of the bit-error ratio (BER) testset and the oscilloscope enable the characterization of the signal after the last round-trip in the loop. The transmission link consists of an $80-\mathrm{km}$ long standard single-mode fiber (SSMF) and a matching length of $13 \mathrm{~km}$ dispersion compensating fiber (DCF).

The FOPA, placed between the SSMF and the $\mathrm{DCF}$, is realized by combining the signal with a CW pump that has been phase modulated with four radio-frequency (RF) tones of frequencies $111 \mathrm{MHz}, 675 \mathrm{MHz}, 1 \mathrm{GHz}$ and $2.25 \mathrm{GHz}$ for stimulated Brillouin scattering (SBS) mitigation, before being amplified by a high-power EDFA. The pump and signal are combined in a Mach-Zehnder interferometer add/drop multiplexer with fiber Bragg gratings (FBGs) reflective at the pump wavelength in each arm. This solution enables to simultaneously achieve less than $1 \mathrm{~dB}$ coupling loss for the transmitted signal/reflected pump and to filter the out-of-band amplified

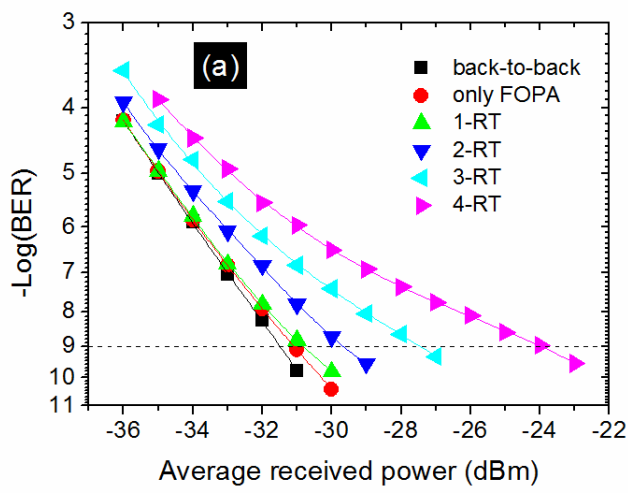

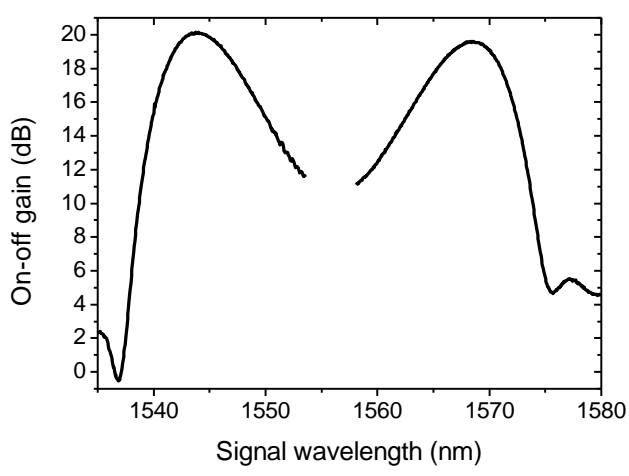

Fig. 2: Measured on-off signal gain spectrum.

spontaneous emission noise from the pump. The parametric amplification, with $20-\mathrm{dB}$ on-off small signal gain at $1545 \mathrm{~nm}$, takes place in a 500-m long highly nonlinear fiber (HNLF) with zerodispersion wavelength at $1550.4 \mathrm{~nm}$, nonlinear coefficient of $10.7 \mathrm{~W}^{-1} \cdot \mathrm{km}^{-1}$, dispersion slope of $0.0185 \mathrm{ps} /\left(\mathrm{nm}^{2} \cdot \mathrm{km}\right)$, and attenuation of $0.7 \mathrm{~dB} / \mathrm{km}$. The pump and signal power at the HNLF input are $28 \mathrm{dBm}$ and $-18 \mathrm{dBm}$, respectively. The measured on-off gain of the FOPA is represented in Fig. 2. The amplified signal is then filtered out by two cascaded thin-film OBPFs with 3-nm and 5-nm bandwidths in order to sufficiently suppress the pump. An EDFA with $28-\mathrm{dB}$ gain and $15-\mathrm{dBm}$ saturated output power is used after the DCF in order to compensate the loss of the rest of the elements in the loop, such as filters, loop switch and couplers. Finally the power in the loop is balanced with an OVA.

The FOPA design used in the present demonstration is polarization sensitive. Therefore it is ensured that a stable principal state of polarization is found for the recirculating loop thanks to polarization controllers (PCs) placed before the loop switch. Polarization matching between the signal and pump is ensured in order to provide maximum parametric gain. This is achieved thanks to another PC placed in the pump path within the FOPA. The receiver consists of an EDFA preamplifier, and a photodiode with $45-\mathrm{GHz}$ bandwidth in the case of OOK, or a 1-bit fiber

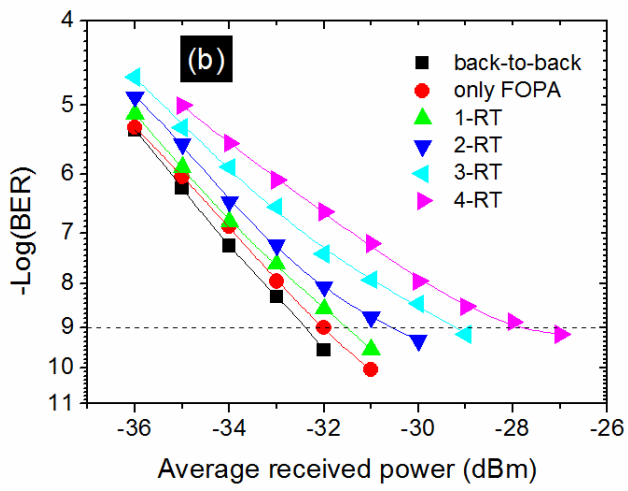

Fig. 3: BER characteristics of 40-Gbit/s CSRZ-OOK (a) and CSRZ-DPSK (b). 


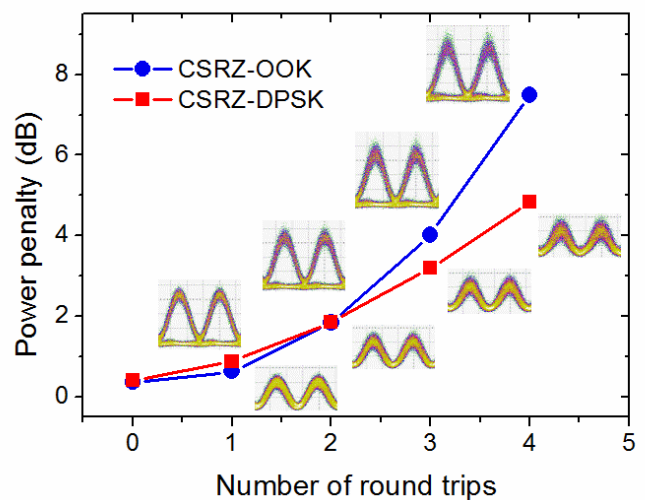

Fig. 4: Power penalty as a function of number of round trips and corresponding eye diagrams for 40-Gbit/s CSRZ-OOK and CSRZ-DPSK signals.

delay interferometer ( $\mathrm{DI}$ ) followed by a balanced detector (BD), also with $45-\mathrm{GHz}$ bandwidth, for DPSK. A loop-compatible clock recovery circuit is also employed at the receiver.

\section{Experimental results}

The performance of the cascaded FOPA is studied for CSRZ-OOK and CSRZ-DPSK modulation at $40 \mathrm{Gbit} / \mathrm{s}$. The optimized average signal power at the input of the SSMF and DCF are $1.4 \mathrm{dBm}$ and $-5 \mathrm{dBm}$, respectively.

BER measurements are carried out as a function of the average received power. The BER performance of the cascaded FOPA for several round trips (RTs) as well as for the FOPA alone (without transmission span) is presented in Fig. 3. Error-free performance is achieved for both modulation formats up to four round trips (RTs), corresponding to $320 \mathrm{~km}$ transmission.

The power penalty as a function of the number of RTs has been extracted for a BER of $10^{-9}$, as shown in Fig. 4. The eye diagrams, taken at the input of the receiver, are also illustrated in the insets of the figure. ' $O$ ' round trip corresponds to the penalty of the FOPA itself when placed between the transmitter and the receiver, which is less than $0.5 \mathrm{~dB}$. When increasing the transmission distance by increasing the number of round trips, the power penalty increases while the pulse shape is well preserved, which suggests that noise accumulation is responsible for signal degradation for both modulation formats. For longer transmission distances the CSRZ-DPSK format shows a lower power penalty thanks to its well known robustness. The difference compared with the CSRZ-OOK format is $2.7 \mathrm{~dB}$ after 4 round trips.

\section{Discussion}

Even though the first cascadability of in-line FOPAs has been demonstrated in the reported experiment, it is clear that further practical advances are needed to make the scheme comparable with EDFAs. Unavoidable phase modulation (PM) of the CW pump in order to suppress stimulated Brillouin scattering impacts the OOK modulated signals more than the DPSK signals. The pump PM affects the phase matching-condition, resulting in modulation of the gain. Moreover, optical filters and HNLF, as dispersive media, may transfer the pump PM into intensity modulation, which further causes signal gain variations through the pump power dependence of the gain. Efficient suppression of the pump and idler requires OBPFs with large extinction ratios to circumvent crosstalk and good cascadability. Multichannel crosstalk mitigation needs to be implemented. Such effects may be negligible for well-designed single FOPAs, but are of an accumulative nature if those are cascaded as in-line amplifiers. Most importantly, polarization-independent configurations using either polarization diversity ${ }^{7}$ or dual-pump FOPAs with orthogonallypolarized pumps ${ }^{8}$ should be implemented to overcome polarization-induced gain changes while providing sufficient signal gain.

\section{Conclusion}

The performance of cascaded single-pump FOPAs has been experimentally investigated for the first time using recirculating loop transmission. The feasibility of exploiting FOPAs as in-line amplifiers was investigated for 40 Gbit/s CSRZ-OOK and CSRZ-DPSK signals. Both modulation formats show error-free performance up to $320 \mathrm{~km}$. The choice of CSRZ-DPSK signals allows to reduce the power penalty by $2.7 \mathrm{~dB}$ compared to CSRZ-OOK. Possible sources of impairments and possible ways to improve the performance of FOPAs as in-line amplifiers have also been discussed.

\section{References}

[1] J. Hansryd et all, IEEE. J. Select. Topics Quantum Electron. 8, 506 (2002).

[2] M. Gao et al., Opt. Express 19, 23258 (2011).

[3] S. Petit et al., IEEE Photon. Technol. Lett. 23, 546 (2011)

[4] N. E. Dahdah et al., IEEE. J. Select. Topics Quantum Electron. 18, 950 (2012).

[5] B. Corcoran et al., Proc. OFC/NFOEC, PDP5A.4 (2012).

[6] M. Matsumoto et al., Optics Express. 15, 8094 (2007).

[7] K. K. Y. Wong et al., IEEE Photon. Technol. Lett. 14, 1506 (2002).

[8] K. K. Y. Wong et al., IEEE Photon. Technol. Lett. 14, 911 (2002). 